\title{
EVAPOTRANSPIRAÇÃO E COEFICIENTES DE CULTURA DO MAMOEIRO PARA A REGIÃO LITORÂNEA DO CEARÁ ${ }^{1}$
}

\author{
AFRÂNIO A. T. MONTENEGRO ${ }^{2}$, FRANCISCO M. L. BEZERRA ${ }^{3}$, \\ RAIMUNDO N. de LIMA ${ }^{4}$
}

\begin{abstract}
RESUMO: O objetivo deste trabalho foi estimar a evapotranspiração da cultura do mamoeiro (Carica papaya L.), bem como seus coeficientes de cultura, sob irrigação, utilizando-se de uma linha de emissores para duas linhas de plantio, com um emissor para quatro plantas. Foi utilizada a variedade "Sunrise Solo", no espaçamento 2,5 m x 2,5 m x 3,5 m, em fileira dupla. A evapotranspiração da cultura foi estimada por meio do método do balanço hídrico, adotando-se um volume de controle de solo com profundidade de 0,6 m. A evapotranspiração de referência (ETo) foi medida em área adjacente, utilizando-se do lisímetro de pesagem e estimada pelo método de Penman-Monteith FAO. A taxa de evapotranspiração média da cultura para o período foi de $3,3 \mathrm{~mm} \mathrm{dia}{ }^{-1}$, sendo $2,2 \mathrm{~mm} \mathrm{dia}^{-1}$ para a fase vegetativa (1);3,2 mm dia ${ }^{-1}$ para a fase de floração/frutificação (2), e 4,3 mm dia ${ }^{-1}$ para a fase de floração/frutificação/maturação (3). Os valores de coeficiente de cultura (Kc), obtidos através da relação ETc/Eto, foram maiores quando a ETo foi medida pelo lisímetro, em relação aos valores de ETo estimados pelo método de Penman-Monteith FAO. Empregando o primeiro método, os valores de Kc foram 0,64; 1,16 e 1,19, enquanto para Penman-Monteith FAO foram 0,54; 0,87 e 0,91, nos estádios $1 ; 2$ e 3 , respectivamente.
\end{abstract}

PALAVRAS-CHAVE: Carica papaya L, tensiômetro, condutividade hidráulica.

\section{EVAPOTRANSPIRATION AND CROP COEFFICIENTS OF PAPAYA IN THE COASTAL REGION OF CEARÁ STATE, BRAZIL}

SUMMARY: The objective of this work was to estimate the evapotranspiration and crop coefficients of papaya (Carica papaya L.), variety "Sunrise Solo", planted in a $2.5 \mathrm{~m}$ x $2.5 \mathrm{~m}$ x $3.5 \mathrm{~m}$ spacing, with one irrigation line of micro-sprinklers for two plant lines, with one emitter operating for four plants. The crop evapotranspiration was evaluated by using the water balance method, in $0.60 \mathrm{~m}$ depth soil volume. The reference evapotranspiration (ETo) was determined using both lysimeter data and Penman-Monteith FAO method. Meteorological data were obtained from Embrapa's Weather Station placed near the experimental plots. Results revealed a mean crop evapotranspiration rate of $3.3 \mathrm{~mm}$ day $^{-1}$, being 2.2 for the vegetative stage (1); 3.2 for the flowering/frutification stage (2), and $4.3 \mathrm{~mm}$ day $^{-1}$ for the flowering/frutification/maturation stage (3). The crop coefficient values (Kc) obtained through ETc/ETo ratio were higher when ETo was measured in comparison with those estimated by Penman-Monteith FAO method. The former method showed values of $0.64 ; 1.16$, and 1.19 , while for the Penman-Monteith FAO method the values were 0.54, 0.87 and 0.91, for the stages 1,2 and 3, respectively.

KEYWORDS: Carica papaya L., tensiometer, hydraulic conductivity.

\footnotetext{
${ }^{1}$ Extraído da Dissertação de Mestrado do primeiro autor.

${ }^{2}$ Eng. Agrônomo, M.Sc. em Irrigação e Drenagem, Pesquisador, Embrapa Agroindústria Tropical, Caixa Postal 3.761, Fortaleza - CE, e-mail: afranio@cnpat.embrapa.br

${ }^{3}$ Eng. Agrônomo, Prof. Doutor, Departamento de Engenharia Agrícola, Centro de Ciências Agrárias, UFC, Fortaleza - CE.

${ }^{4}$ Eng. Agrônomo, M.Sc., Pesquisador, Embrapa Agroindústria Tropical, Fortaleza - CE.

Recebido pelo Conselho Editorial em: 27-6-2003

Aprovado pelo Conselho Editorial em: 21-5-2004
} 


\section{INTRODUÇÃO}

O mamoeiro (Carica papaya L.) é uma das fruteiras mais cultivadas nos países de clima tropical, sendo o Brasil o maior produtor mundial, com 1,4 milhão de toneladas por ano, que representa $25,8 \%$ da produção total (FAO, 2001).

MANICA \& OLIVEIRA JÚNIOR (2000), estudando os dados da FAO de produção mundial de mamão, no período de 1990 a 1999, concluíram que a cultura esteve em expansão na última década. A exportação mundial de mamão cresceu 133,19\% nos 10 anos analisados, passando de 55.833 para 127.866 toneladas, em 1998, gerando 105.280 mil dólares.

Nessa mesma década, enquanto o Brasil aumentou sua área plantada de 16.130 para 39.055 ha (142\%), o Ceará passou de 252 para 1.382 hectares (448\%), aumentando sua produção de 6.380 mil para 40.271 mil frutos $(531 \%)$, e saltando da $7^{7 \underline{a}}$ para a $4^{\mathrm{a}}$ posição entre os maiores produtores do País (IBGE, 2001).

Entretanto, apesar da expansão da cultura e da demanda por tecnologia, são poucas as informações acerca das necessidades hídricas do mamoeiro, que possam subsidiar o manejo das irrigações, principalmente no Ceará.

As estimativas das lâminas de água a aplicar e da frequiência de irrigação das culturas são de grande importância para evitar a redução nos rendimentos, provocada pelo excesso ou déficit de umidade no solo, salinização, devido à drenagem deficiente, e compactação por excesso de umidade durante as operações de preparo do solo (SILVA et al., 1981).

Praticamente, toda a água de que as plantas necessitam, é extraída pelo sistema radicular e perdida para a atmosfera por meio do processo de evapotranspiração, sendo necessário que a mesma seja devolvida à planta, na forma de precipitação ou irrigação, sob pena de comprometer o desenvolvimento e a produção da cultura.

Portanto, o estudo da evapotranspiração e a estimativa dos coeficientes de cultura são de fundamental importância para o manejo adequado de projetos de irrigação, contribuindo para o aumento da produtividade e otimização do uso da energia elétrica e dos recursos hídricos, cada vez mais escassos.

BEZERRA et al. (2001), trabalhando com a cultivar "Sunrise Solo", utilizando o método do balanço hídrico até a fase de floração da cultura, no município de Fortaleza - CE, encontraram valores médios de evapotranspiração do mamoeiro, variando de $2,3 \mathrm{~mm} \mathrm{dia}^{-1}$, na fase inicial, até $6,8 \mathrm{~mm} \mathrm{dia}^{-1}$, no $88^{\circ}$ dia após o plantio. Os valores de Kc revelaram-se diferentes em função dos métodos de estimativa da ETo utilizados. Para o método de Penman-Monteith, o coeficiente de cultura variou de 0,41 (fase inicial da cultura) a 1,16 (início da floração) e, para o método do tanque Classe A, de 0,40 a 1,20. Os valores médios foram de 0,74 a 0,75 para a fase inicial, e de 1,09 a 1,12 no início da floração, para o primeiro e o segundo métodos, respectivamente.

Dessa forma, o presente trabalho foi desenvolvido com o objetivo de determinar a evapotranspiração e os coeficientes de cultura do mamoeiro, nas condições do litoral do Ceará, durante o primeiro ano de implantação da cultura, utilizando o método do balanço hídrico no solo.

\section{MATERIAL E MÉTODOS}

O experimento foi conduzido no Campo Experimental do Curu, pertencente à Embrapa Agroindústria Tropical, em uma área de 0,57 hectares, cujas coordenadas geográficas são: latitude $3^{\circ} 28^{\prime} 47^{\prime \prime} \mathrm{S}$, longitude $39^{\circ} 09^{\prime} 47^{\prime \prime} \mathrm{W}$ e altitude de $31 \mathrm{~m}$. O campo experimental faz parte do projeto de irrigação Curu-Paraipaba, situado na região Norte do Ceará, município de Paraipaba, no trecho final da bacia do Rio Curu. 
De acordo com o critério de classificação climática de Köeppen (1918), reforçado pelo algoritmo da classificação de Köeppen (VIANA et al. 1997), Paraipaba apresenta clima do tipo Aw, classificado como tropical chuvoso, clima de savana, e se caracteriza por apresentar o máximo de chuvas no outono e período seco no inverno. Segundo AGUIAR et al. (2001), baseados na média de 1975 a 2000, o município de Paraipaba apresenta precipitação média anual de $985 \mathrm{~mm}$, evaporação de 2.624 mm, umidade relativa de $86 \%$ e temperatura média anual de $27,1^{\circ} \mathrm{C}$.

O solo do local apresenta relevo plano e, segundo o novo Sistema Brasileiro de Classificação de Solos, está classificado como Neossolo Quartzarênico (EMBRAPA, 1999).

Neste estudo, foi utilizada a cultura do mamoeiro, variedade "Sunrise Solo", pertencente ao grupo "Solo". As mudas foram produzidas no Campo Experimental de Pacajus, pertencente à Embrapa Agroindústria Tropical, utilizando-se de tubetes com substrato de casca de arroz carbonizada, barro preto e esterco, na proporção 3:2:2. A semeadura foi realizada em 9-3-2000, utilizando-se de duas sementes em cada tubete. $\mathrm{O}$ desbaste ocorreu 20 dias após a semeadura, deixando-se apenas uma planta em cada tubete.

O preparo da área constou de gradagem e abertura de 672 covas, distanciadas $2,5 \mathrm{~m} \mathrm{x} \mathrm{2,5} \mathrm{m} \mathrm{x}$ 3,5 m, em fileira dupla. As covas foram abertas na dimensão de $0,40 \mathrm{~m}$ de profundidade e $0,30 \mathrm{~m}$ de diâmetro, com o auxílio de um perfurador de solo com broca helicoidal, acoplado ao sistema hidráulico de um trator.

A adubação de plantio foi realizada em 14-4-2000, utilizando-se dos seguintes fertilizantes por cova: esterco de gado (5 L), superfosfato simples (330 g) e FTE "Fritted Trace Elements" BR-12 (50 g). O plantio definitivo foi realizado no dia 19-4-2000, 40 dias após a semeadura, utilizando-se de três mudas por cova.

Foram instalados 32 tensiômetros com manômetro de mercúrio, distribuídos em oito baterias, nas profundidades de 0,$10 ; 0,30 ; 0,50$ e $0,70 \mathrm{~m}$. Cada bateria foi instalada ao lado de uma planta, aleatoriamente dentro da parcela, e cada parcela experimental recebeu duas baterias de tensiômetros. A leitura da altura da coluna de mercúrio foi realizada diariamente, às $8 \mathrm{~h}$ da manhã, no período de 295-2000 a 27-3-2001, quando as plantas completaram um ano de idade.

As curvas de retenção de água no solo foram obtidas nos Laboratórios de Hidráulica e Irrigação, (Departamento de Engenharia Agrícola) e de Física do Solo (Departamento de Ciência do Solo), ambos pertencentes à Universidade Federal do Ceará. Para isso, foram coletadas previamente 104 amostras de solo indeformadas na área do experimento, utilizando-se do cilindro de Uhland, nas profundidades de 0,$10 ; 0,30 ; 0,50$ e $0,70 \mathrm{~m}$. A partir dos valores de umidade dessas amostras submetidas a diferentes tensões, utilizou-se o modelo de GENUCHTEN (1980) para obtenção dos parâmetros empíricos (Tabela 1), por meio do software Soil Water Retention Curve - SWRC. Com esses parâmetros, foram traçadas as curvas características da água no solo, nas profundidades de 0,10 ; 0,$30 ; 0,50$ e $0,70 \mathrm{~m}$ (Figura 1).

TABELA 1. Valores dos parâmetros $\alpha, \mathrm{m}, \mathrm{n}, \theta_{\mathrm{r}}$ e $\theta_{\mathrm{s}}$ do modelo de Genuchten e densidade do solo para as profundidades de 0,10;0,30; 0,50 e 0,70 m, de um Neossolo Quartzarênico.

\begin{tabular}{ccccccc}
\hline $\begin{array}{c}\text { Profundidade } \\
(\mathrm{m})\end{array}$ & $\begin{array}{c}\alpha \\
\left(\mathrm{m}^{-1}\right)\end{array}$ & $\mathrm{m}$ & $\mathrm{n}$ & $\begin{array}{c}\theta_{\mathrm{r}} \\
\left(\mathrm{m}^{3} \mathrm{~m}^{-3}\right)\end{array}$ & $\begin{array}{c}\theta_{\mathrm{s}} \\
\left(\mathrm{m}^{3} \mathrm{~m}^{-3}\right)\end{array}$ & $\begin{array}{c}\text { Densidade } \\
\left(\mathrm{kg} \mathrm{m}^{-3}\right)\end{array}$ \\
\hline 0,10 & 0,0566 & 0,0857 & 10,6028 & 0,035 & 0,414 & 1,55 \\
0,30 & 0,0494 & 0,2057 & 4,1600 & 0,028 & 0,372 & 1,50 \\
0,50 & 0,0551 & 0,0695 & 16,9907 & 0,032 & 0,361 & 1,55 \\
0,70 & 0,0645 & 0,1094 & 6,6017 & 0,037 & 0,377 & 1,55 \\
\hline
\end{tabular}




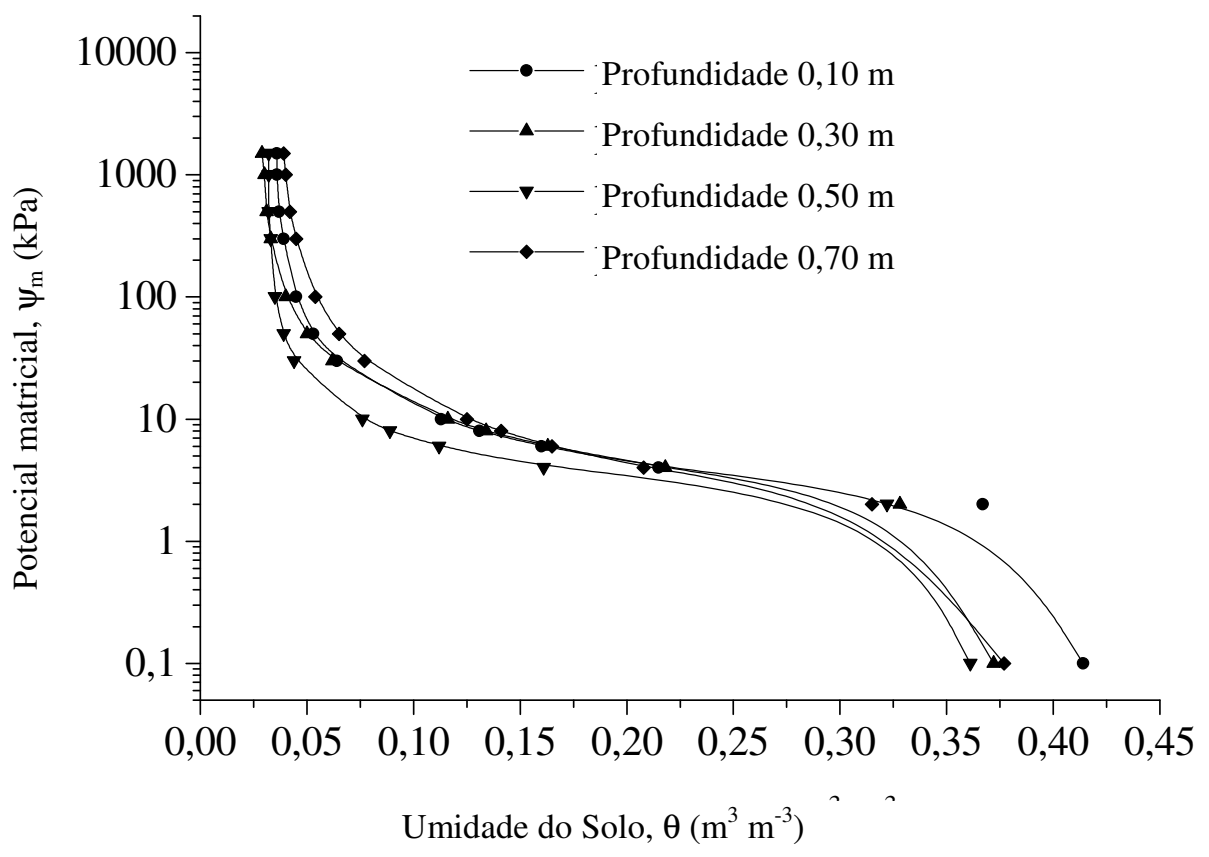

FIGURA 1. Curvas características da água em Neossolo Quartzarênico, na área do experimento, nas profundidades de 0,$10 ; 0,30 ; 0,50$ e $0,70 \mathrm{~m}$.

A cultura foi irrigada por um sistema de irrigação localizada, tipo microaspersão, utilizando-se de uma linha de emissores para duas linhas de plantio, com um emissor para quatro plantas, numa disposição de $6 \mathrm{~m}$ entre linhas e $5 \mathrm{~m}$ entre emissores. Os microaspersores utilizados apresentaram vazão de $53 \mathrm{~L} \mathrm{~h}^{-1}$ e raio de molhamento de $3,5 \mathrm{~m}$, para uma pressão de serviço de $196,1 \mathrm{kPa}$. As irrigações foram realizadas sempre pela manhã, imediatamente após a leitura dos tensiômetros. A fonte hídrica do experimento foi o Rio Curu, perenizado pelas águas dos açudes General Sampaio, Pereira de Miranda, Caxitoré, Frios e Tejussuoca. Sua classificação é $\mathrm{C}_{2} \mathrm{~S}_{1}$, que representa, segundo RICHARDS (1954), água com salinidade média e baixo conteúdo de sódio.

As adubações com nitrogênio, fósforo, potássio, magnésio, zinco e boro foram efetuadas, via fertirrigação, com parcelamento semanal, utilizando-se dos seguintes produtos: uréia, fosfato monoamônico - MAP, cloreto de potássio, sulfato de magnésio, sulfato de zinco e ácido bórico, respectivamente. A quantidade total de nutrientes, determinada pela análise de solo, foi dividida em parcelas mensais, de acordo com a curva de absorção da cultura.

A floração teve início em 14-6-2000, 55 dias após o plantio definitivo. Nesse momento, deu-se início à operação de desbaste, deixando-se uma planta em cada cova, dando-se preferência às hermafroditas. A primeira colheita foi realizada sete meses após o plantio definitivo, no dia 22-112000, passando a apresentar freqüência semanal.

O controle fitossanitário foi realizado sempre que apareciam os primeiros sintomas de pragas e doenças na cultura.

O balanço hídrico do mamoeiro foi realizado no período de 29-5-2000, 40 dias após o plantio definitivo das mudas, até 27-3-2001, totalizando 302 dias. O período total do balanço foi dividido em intervalos compreendidos entre as leituras tensiométricas realizadas antes do início das irrigações e/ou ocorrências de chuva, oferecendo, portanto, oportunidade para que a água infiltrada pudesse ser 
plenamente redistribuída ao longo do perfil do solo. Dessa forma, ocorreram 47 intervalos, com duração entre três e nove dias.

Os dados de precipitação pluvial utilizados neste trabalho foram coletados na estação agrometeorológica do Campo Experimental do Curu, localizada nas proximidades do experimento. A pluviosidade foi registrada diariamente, às $8 \mathrm{~h}$, para todo o período do balanço. Foi considerada como precipitação efetiva, $75 \%$ da precipitação total no período.

As lâminas de irrigação aplicadas foram definidas com base no potencial matricial, mantendo-se o solo próximo à capacidade de campo. Para a obtenção do componente irrigação (I), foi utilizada a vazão dos microaspersores $\left(53 \mathrm{~L} \mathrm{~h}^{-1}\right)$ relacionada com a área transversal do bulbo úmido $\left(9,61 \mathrm{~m}^{2}\right)$, resultando em uma lâmina de 5,5 mm para cada hora de irrigação.

Para a determinação dos componentes da drenagem profunda e ascensão capilar para a profundidade de $0,6 \mathrm{~m}$, foi utilizada a equação de Buckingham-Darcy, escrita de maneira simplificada por REICHARDT (1985), da seguinte forma:

$$
\mathrm{qz}=-\mathrm{K}(\theta) \frac{\Delta \Psi \mathrm{t}}{\Delta \mathrm{Z}}
$$

em que,

qz - fluxo de água;

$K(\theta)$ - condutividade hidráulica do solo não-saturado na profundidade $Z$, em função da umidade do solo, e

$\frac{\Delta \Psi}{\Delta Z}$ - gradiente do potencial total da água no solo, na profundidade $\mathrm{Z}$.

Aplicando a eq.(1) para a direção vertical, na profundidade máxima do volume de controle do solo, $\mathrm{Z}=0,6 \mathrm{~m}$, obtém-se a seguinte equação:

$$
\mathrm{qz}=-\mathrm{K}(\theta)_{0,6}\left\{\frac{\psi_{\mathrm{T}} 50-\psi_{\mathrm{T}} 70}{20}\right\}_{0,6}
$$

em que,

$\mathrm{K}(\theta)_{0,6}$ - condutividade hidráulica do solo não-saturado em função da umidade média do solo $(\theta)$, na profundidade de $0,6 \mathrm{~m}$;

$\left\{\frac{\psi_{\mathrm{T}} 0,5-\psi_{\mathrm{T}} 0,7}{0,2}\right\}_{0,6}$ - gradiente do potencial total da água no solo na profundidade de 0,6 m;

$\psi_{\mathrm{T}} 0,5$ - potencial da água no solo na profundidade de $0,5 \mathrm{~m}$, em $\mathrm{cm} \mathrm{H}_{2} \mathrm{O}$, e

$\psi_{\mathrm{T}} 0,7$ - potencial da água no solo na profundidade de $0,7 \mathrm{~m}$, em $\mathrm{cm} \mathrm{H}_{2} \mathrm{O}$.

Para a obtenção da equação que permite calcular os valores de $K(\theta)_{0,6}$, foi realizado um ensaio de campo ao lado do experimento, no período de 8-6 a 7-8-2000, totalizando 61 dias de observação, conforme metodologia de HILLEL et al. (1972). A equação obtida que define a condutividade hidráulica a $0,6 \mathrm{~m}$ de profundidade é expressa da seguinte forma:

$$
\mathrm{K}(\theta)_{0,6}=0,0013 \mathrm{e}^{77,668 \theta}
$$

em que,

$\mathrm{K}(\theta)_{0,6}$ - condutividade hidráulica do solo não-saturado em função da umidade média do solo $(\theta)$ na profundidade de $0,6 \mathrm{~m}$, e

e - base do logaritmo neperiano. 
A variação do armazenamento da água do solo, no intervalo de tempo considerado, para a profundidade adotada para o balanço $(0,6 \mathrm{~m})$, foi obtida pela expressão de REICHARDT (1985):

$$
\Delta \mathrm{A}=\left(\bar{\theta}_{2}-\bar{\theta}_{1}\right) \mathrm{Z}
$$

em que,

$\Delta$ A- variação do armazenamento da água do solo, umidade;

$\bar{\theta}_{2}$ - umidade média do perfil até a profundidade de $0,6 \mathrm{~m}$, no dia da irrigação, $\mathrm{m}^{3} \mathrm{~m}^{-3}$;

$\bar{\theta}_{1}$ - umidade média do perfil até a profundidade de $0,6 \mathrm{~m}$, no dia da irrigação anterior, $\mathrm{m}^{3} \mathrm{~m}^{-3}$, e

$\mathrm{Z}$ - profundidade adotada para o balanço, $0,6 \mathrm{~m}$.

A variação total do armazenamento de água no perfil, que vai da superfície do solo até a profundidade de $0,6 \mathrm{~m}$, foi obtida pela soma das variações parciais em cada camada. Considerou-se que os tensiômetros instalados a 0,$10 ; 0,30$ e $0,50 \mathrm{~m}$ monitoravam o potencial matricial médio nas camadas de 0 a 0,$20 ; 0,20$ a 0,40 e 0,40 a 0,60 m, respectivamente.

O componente escoamento superficial (ES) não foi considerado no presente trabalho pelo fato de a área apresentar pequena declividade e o controle das irrigações não ter permitido a ocorrência de deflúvio superficial.

Como os componentes precipitação pluvial, irrigação, fluxo (percolação ou ascensão capilar) e armazenamento foram medidos e/ou calculados e o escoamento superficial foi excluído, a evapotranspiração foi determinada utilizando a equação do balanço hídrico, escrita da seguinte forma:

em que,

$\mathrm{ET}=\mathrm{P}+\mathrm{I} \pm \mathrm{qz}-\Delta \mathrm{A}$

ET - evapotranspiração da cultura, mm;

$\mathrm{P}$ - precipitação efetiva, mm;

I - irrigação, mm;

qz - percolação, quando negativo, ou ascensão capilar, quando positivo, mm, e

$\Delta \mathrm{A}$ - variação do armazenamento da água do solo na camada de profundidade de zero a Z, para o intervalo de tempo considerado no balanço.

A evapotranspiração de referência (ETo) foi determinada diretamente, utilizando-se de um lisímetro de pesagem, e estimada pelo método de Penman-Monteith FAO.

O lisímetro utilizado é do tipo caixa metálica e mede 1,5 m x 1,5 m, com 1,0 m de profundidade. Foi instalado a uma distância de $800 \mathrm{~m}$ do experimento, no centro de uma área de 1 ha, cultivada com grama-gengibre (Paspalum maritimum L.) irrigada por aspersão convencional, apoiado sobre uma balança eletrônica, ligada a uma estação micrometeorológica automática por meio de cabos. As leituras de variação do peso do bloco de solo isolado com grama no interior do lisímetro eram registradas e armazenadas em um microprocessador eletrônico (datalogger), conforme recomendações de MIRANDA et al. (1999), e posteriormente transferidas para planilhas eletrônicas para cálculo da ETo. Os dados climáticos utilizados na estimativa da ETo pelo método de Penman-Monteith FAO foram fornecidos pela estação agrometeorológica da Embrapa, instalada nas proximidades do experimento.

Utilizando os valores diários da evapotranspiração de referência (ETo), medidos diretamente pelo lisímetro e estimados pelo método de Penman-Monteith FAO, e os valores da evapotranspiração da cultura obtidos no balanço hídrico, foram calculados os coeficientes de cultura $(\mathrm{Kc})$ nas diferentes fases fenológicas, por meio da expressão apresentada por DOORENBOS \& KASSAM (1979), como:

$$
\mathrm{Kc}=\frac{\mathrm{ETc}}{\mathrm{ETo}}
$$


sendo,

ETc - evapotranspiração da cultura, $\mathrm{mm} \mathrm{dia}^{-1}$, e

ETo - evapotranspiração de referência, $\mathrm{mm} \mathrm{dia}^{-1}$.

\section{RESULTADOS E DISCUSSÃO}

A lâmina total de água acumulada, aplicada durante o período do balanço hídrico por meio da irrigação, atingiu 1.141,2 mm. Comparando esse valor com a evapotranspiração acumulada no mesmo período $(994,4 \mathrm{~mm})$, constata-se que a cultura não sofreu restrição de água, tendo recebido uma lâmina bastante superior as suas necessidades hídricas, em praticamente todos os intervalos estudados. A precipitação efetiva, considerada como $75 \%$ da precipitação total, foi de $258,4 \mathrm{~mm}$ para todo o período do balanço.

Com relação à variação no armazenamento, verificou-se uma amplitude de $-11,3 \mathrm{~mm}$ a $+12,1 \mathrm{~mm}$. Isso evidencia que novas lâminas de irrigação foram aplicadas em períodos de baixo conteúdo de água no solo, e em outros quando havia excesso de umidade.

O fluxo descendente, que mostra as perdas de água por drenagem profunda provocada por excesso de umidade no solo, revela que foram percolados $433,1 \mathrm{~mm}$ durante todo o período estudado. A textura arenosa do solo, somada às altas lâminas de irrigação e precipitação, favoreceu a ocorrência do fenômeno. No caso de negligência desse componente, os seus valores são acrescidos à evapotranspiração da cultura, o que comprova, conforme REICHARDT (1985), que a drenagem profunda não pode ser desprezada sem justificativa experimental.

A taxa média de ETc foi de 3,3 $\mathrm{mm} \mathrm{dia}^{-1}$, totalizando $994,4 \mathrm{~mm}$ para todo o período. Com relação aos estádios fenológicos da cultura, obtiveram-se $2,2 \mathrm{~mm}$ dia $^{-1}$ para a fase vegetativa, 3,2 $\mathrm{mm} \mathrm{dia}^{-1}$ para a fase de floração/frutificação e $4,3 \mathrm{~mm} \mathrm{dia}^{-1}$ para a fase de floração/frutificação/ maturação dos frutos.

Para a fase inicial, os resultados assemelham-se bastante aos obtidos por BEZERRA et al. (2001), que trabalhando com a mesma variedade, nas condições de Fortaleza - CE, encontraram uma taxa média de ETc de $2,3 \mathrm{~mm} \mathrm{dia}^{-1}$. Para a fase de floração/frutificação/maturação, entretanto, verificou-se, neste trabalho, uma taxa máxima de ETc de 5,6 $\mathrm{mm} \mathrm{dia}^{-1}$, revelando evapotranspiração máxima da cultura inferior àquela obtida por BEZERRA et al. (2001), que, no $88^{\circ}$ dia após o plantio, atingiu $6,8 \mathrm{~mm} \mathrm{dia}^{-1}$.

Os valores de Kc para os diferentes estádios de desenvolvimento, calculados com base nos valores da ETo medidos pelo lisímetro e estimados pelo método de Penman-Monteith FAO, encontram-se na Tabela 2. A fase vegetativa foi considerada a partir do início do balanço hídrico, 84 dias após a semeadura das mudas (40 dias após o plantio definitivo), até a constatação de floração em $40 \%$ das plantas. Para a fase de floração/frutificação, considerou-se o período do final da fase vegetativa até antes da primeira colheita. E, finalmente, a partir da primeira colheita até o final do período do balanço hídrico, foi considerada a fase de floração/frutificação/maturação dos frutos.

TABELA 2. Coeficientes de cultura do mamoeiro nas diferentes fases da cultura, a partir da ETo medida no lisímetro e estimada pelo método de Penman-Monteith FAO.

\begin{tabular}{lccc}
\hline $\begin{array}{l}\text { Dias Após a } \\
\text { Semeadura }\end{array}$ & Estádios & Kc Lisímetro & $\begin{array}{c}\text { Kc Penman - } \\
\text { Monteith FAO }\end{array}$ \\
\hline $84-107$ & Vegetativo & 0,64 & 0,54 \\
$115-260$ & Floração/Frutificação & 1,16 & 0,87 \\
$267-380$ & Floração/Frutificação/Maturação & 1,19 & 0,91 \\
\hline
\end{tabular}


Os valores de ETo estimados pelo método de Penman-Monteith FAO mostraram-se sempre superiores aos medidos pelo lisímetro, reforçando os resultados obtidos por OLIVEIRA (1999) e DIAS (2001), que utilizaram o mesmo equipamento. Consequientemente, os valores do Kc obtidos por meio da ETo medidos pelo lisímetro revelaram-se maiores do que aqueles obtidos, utilizando-se do método de Penman-Monteith FAO. O manejo inadequado na área do lisímetro pode ter afetado o crescimento da grama, a uniformidade da altura e a cobertura da superfície, provocando uma medição subestimada da evapotranspiração de referência.

Dessa forma, os valores de Kc encontrados para os estádios vegetativo, floração/frutificação e floração/frutificação/maturação foram 0,$64 ; 1,16$ e 1,19, respectivamente, quando se utilizou o lisímetro, e 0,54; 0,87 e 0,91 utilizando o método de Penman-Monteith FAO. Considerando todo o período, tem-se um Kc médio de 1,11 e 0,85 para o primeiro e o segundo métodos, respectivamente.

Pela Tabela 2, verifica-se que o valor médio do coeficiente de cultura obtido na fase de floração/frutificação, quando se utilizou o lisímetro, foi de 1,16, coincidindo com o Kc obtido por BEZERRA et al. (2001), utilizando o método de Penman-Monteith FAO, no início da floração.

\section{CONCLUSÕES}

Os valores de ETo apresentaram variação em função do método utilizado, embora tenham mostrado a mesma tendência ao longo do período. Os valores medidos diretamente pelo lisímetro mantiveram-se inferiores àqueles estimados pelo método de Penman-Monteith FAO. Conseqüentemente, os valores de $\mathrm{Kc}$ obtidos por meio da ETo medida no lisímetro, revelaram-se maiores do que aqueles obtidos utilizando-se da ETo estimada pelo método de Penman-Monteith FAO.

Considerando todo o período do balanço hídrico no solo, obteve-se um coeficiente de cultura médio de 1,11, utilizando os dados de ETo medidos no lisímetro. Com a ETo estimada pelo método de Penman-Monteith FAO, o Kc médio obtido foi de apenas 0,85.

O maior registro de demanda hídrica ocorreu na fase fenológica de floração/frutificação/ maturação, em que a evapotranspiração da cultura atingiu 5,6 $\mathrm{mm} \mathrm{dia}^{-1}$. A taxa média de ETc para todo o período foi $3,3 \mathrm{~mm} \mathrm{dia}^{-1}$.

\section{REFERÊNCIAS BIBLIOGRÁFICAS}

AGUIAR, M.J.N.; LIMA, J.B.; CARNEIRO, F.A.; BADU, F.O. Dados climatológicos: Estação de Paraipaba, 2000. Fortaleza: Embrapa-CNPAT, 2001. 14 p. (Boletim Agrometeorológico, 1).

BEZERRA, F.M.L.; MESQUITA, T.B.; OLIVEIRA, C.H.C. Evapotranspiração e coeficientes de cultura do mamão irrigado por sistema de irrigação localizada. In: CONGRESSSO BRASILEIRO ENGENHARIA AGRÍCOLA, 30., 2001, Foz do Iguaçu. Anais...Cascavel: Sociedade Brasileira de Engenharia Agrícola, 2001. 1 CD ROM.

DIAS, K.L.C. Análise da evapotranspiração de referência da grama (Paspalum maritimum L.) e da evapotranspiração do melão (Cucumis melo L.) para a região litorânea do Ceará. $2001.70 \mathrm{f}$. Dissertação (Mestrado em Irrigação e Drenagem) - Universidade Federal do Ceará, Fortaleza, 2001.

DOORENBOS, J.; KASSAM, A.H. Efectos del água sobre el rendimento de los cultivos. Roma: FAO, 1979. 212 p. (Estudio FAO: Riego y Drainage, 33)

EMBRAPA. Centro Nacional de Pesquisa de Solos. Sistema brasileiro de classificação de solos. Brasília: Embrapa Produção de Informação. Rio de Janeiro: EMBRAPA Solos, 1999. 412 p. 
FAO-FOOD AND AGRICULTURE ORGANIZATION OF THE UNITED NATIONS. Statistical databases. Disponível em: <http://www.fao.org>. Acesso em: 2 outubro 2001.

GENUCHTEN, M.T. van. A closed-form equation for predicting the hydraulic conductivity of unsatured soils. Soil Science Society of American Journal, Madison, v.44, n.5, p.892-8, 1980.

HILLEL, D.; KRENTOS, V.D.; STYLIANOU, Y. Procedure and test of an internal drainage method for measuring soil hydraulic characteristics in situ. Soil Science, Madison, v.114, n.5, p.395-400, 1972.

IBGE - INSTITUTO BRASILEIRO DE GEOGRAFIA E ESTATÍSTICA. Indicadores conjunturais, Agropecuária, Produção Agrícola. Disponível em: < http://www.ibge.gov.br>. Acesso em: 2 outubro 2001.

KÖEPPEN, W. Climatologia: con un estudio de los climas de la tierra. México: Fondo de Cultura Economica, 1918. 478 p.

MANICA, I.; OLIVEIRA JÚNIOR, M.E. Produção e comércio de mamão no mundo. In: CONGRESSO BRASILEIRO DE FRUTICULTURA, 16., 2000, Fortaleza. Resumos... Fortaleza: Embrapa Agroindústria Tropical/Sociedade Brasileira de Fruticultura, 2000. p.397.

MIRANDA, F.R. de; YODER, R.E.; SOUZA, F. de. Instalação e calibração de um lisímetro de pesagem no projeto de irrigação Curu-Paraipaba, CE. Revista Brasileira de Engenharia Agrícola e Ambiental, Campina Grande, v.3, n.1, p.107-10, 1999.

OLIVEIRA, J.J.G. Evapotranspiração máxima e coeficientes de cultivo da melancia (Citrullus lanatus, Schrad) através de lisímetro de pesagem de precisão para a região litorânea do Ceará. 1999. $121 \mathrm{f}$. Dissertação (Mestrado em Irrigação e Drenagem) - Universidade Federal do Ceará, Fortaleza, 1999.

REICHARDT, K. Processo de transferência no sistema solo-planta-atmosfera. 4.ed. Campinas: Fundação Cargill, 1985. 466 p.

RICHARDS, L.A. (Ed.) Diagnosis and improvement of saline and alkali soils. Washington: U.S. Salinity Laboratory, 1954. 160 p. (Agriculture Handbook, 60).

SILVA, M.A.; CHOUDHURY, E.N.; GUROVICH, L.A.; MILLAR, A.A. Metodologia para determinar as necessidades de água das culturas irrigadas. Petrolina: EMBRAPA-CPATSA, 1981. 85 p. (Boletim de Pesquisa, 4)

VIANA, T.V.A.; BASTOS, E.A.; ALVES, D.R.B.; FOLEGATTI, M.V. Algoritmo da classificação climática de Köeppen. In: CONGRESSSO BRASILEIRO DE AGROMETEOROLOGIA, 10., 1997, Piracicaba. Anais...Piracicaba: Sociedade Brasileira de Agrometeorologia, 1997. p.255. 